\title{
Professional learning networks: From teacher learning to school improvement?
}

\author{
Rilana Prenger ${ }^{1} \cdot$ Cindy L. Poortman ${ }^{2} \cdot$ Adam Handelzalts $^{3}$ \\ Published online: 2 May 2020 \\ (c) The Author(s) 2020
}

\begin{abstract}
Professional learning communities are promising for teacher learning and improving the quality of education. In the past decade, there has been a shift in focus from within-school to cross-school PLCs: Professional Learning Networks. Knowledge of the underlying working processes of teacher learning in PLNs is scarce. This is even more complicated for PLNs, because of organizational, geographic and professional boundaries. The purpose of this study is to explore how PLNs can function to meet their objectives and what challenges they face in their aim of achieving sustainable teacher learning and school improvement. We applied a qualitative case study design. Data were collected by means of interviews with PLN participants and external coaches, logs by external coaches, and yearly observations by the researchers. Results show how the PLN context influences the outcomes in terms of teacher learning, PLN products and application in their schools. Findings show how leadership, the perception of a shared goal, structured activities, collaboration, and facilitation and support especially appear to influence outcomes. PLNs face additional challenges in relation to within-school PLCs, in terms of knowledge transfer from the PLN back to participants' own schools and the network as a whole. This should be acknowledged and acted upon before PLNs are even established.
\end{abstract}

Keywords Interconnected model $\cdot$ Professional learning networks $\cdot$ Teacher professional development

Cindy L. Poortman

c.1.poortman@utwente.nl

1 Saxion University of Applied Sciences, Enschede, The Netherlands

2 Department of Teacher Development, University of Twente, P.O. Box 217, 7500 AE Enschede, The Netherlands

3 Vrije Universiteit Amsterdam, Amsterdam, The Netherlands 


\section{Introduction}

Teacher collaboration in professional learning communities (PLCs) is a promising form of professional development that improves the quality of education (Doğan and Adams 2018; Stoll 2015; Vescio et al. 2008). PLCs consist of teachers, and sometimes school leaders, working together to improve their teaching and students' learning at their school (Lomos et al. 2011; Stoll et al. 2006). Studies have found that PLCs can lead to changes in teachers' perceptions, and evidence has also been found regarding effects on teachers' practices and students' learning as a result of what is learned in PLCs (Lomos et al. 2011; Vescio et al. 2008). Teachers' professional communities are directly responsible for students' learning according to Louis et al. (2010). A meta-analysis by Lomos et al. (2011) reported that a professional community within a school environment can enhance student achievement, for example, in the areas of mathematics, science, and reading (see also Lai and McNaughton 2016). Others have found evidence for greater teacher satisfaction, higher morale and commitment, and greater effectiveness in the classroom. Students were also more enthusiastic (Andrews and Lewis 2004; Huffman and Jacobson 2003). On the other hand, effects are often mixed, however, and many factors need to be in place before PLCs seem to be able to be successful (Prenger et al. 2017; Lee and Lee 2018). There is still much to learn about the process of professional collaboration and the conditions influencing this collaboration (Gore et al. 2017; Doğan and Adams 2018; Vangrieken et al. 2017).

Moreover, policy-makers, researchers and practitioners are increasingly focused on cross-school PLCs: 'Professional Learning Networks' (PLNs) to facilitate teacher development and encourage school and school system improvement (Poortman and Brown 2018). According to Stoll (2010, p. 4), 'the increased complexity of a fast-changing world has brought new challenges for schooling that are too great for those in any one school to address alone'. This means that improvement in educational systems requires a shift in emphasis from within- to crossschool improvement (Chapman 2014). Although resting on similar assumptions about how teachers learn and change their practice (Stoll et al. 2006), advantages of PLNs could be the wider range of resources and expertise than single schools, greater opportunities for both self-reflection and collective reflection on practice, and increased engagement with more challenging and interactive forms of professional learning (Lieberman 2000; Lieberman and Grolnick 1996). Professional development is not limited to the teachers at one school, but could, in theory, lead to system-wide changes (e.g., Harris and Jones 2010; Hadfield and Ainscow 2018). Poortman and Brown (2018) define Professional Learning Networks as any group who engage in collaborative learning with others outside of their everyday community of practice, in order to improve teaching and learning in their school(s) and/or the school system more widely (p. 1). This encompasses a range of cross-school network types, including research-use teams, multi-site Lesson Study teams and teacher design teams (Poortman and Brown 2018).

So far, there is little systematic research available about how PLNs work in terms of their key features (Chapman 2014; Katz and Earl 2010; Prenger et al. 
2017; Vescio et al. 2008). To facilitate teachers' professional development, 'we must understand the process by which teachers grow professionally and the conditions that support and promote that growth' (Clarke and Hollingsworth 2002, p. 947). According to Doğan and Adams (2018), the direct link between teacher learning in communities and networks and student learning is hard to show. Knowledge of the underlying processes of teacher learning in PLNs is needed in order to understand how the key features of PLNs contribute to teacher learning. This is especially necessary as few articles have specified how learning happens or offered an understanding of the processes that are involved in teachers' work in (Horn and Little 2010; Van Lare and Brazer 2013; Bauer et al. 2015). For PLNs, this is further complicated by their nature, which includes organizational, geographic and professional boundaries (Chapman 2014). Varying contextual influences come into play from the different schools and areas in which PLNs operate (Van Lare and Brazer 2013; Bauer et al. 2015). This study, therefore, describes processes, influential factors and outcomes of a variety of PLNs to explore how they can work to meet their objectives and the challenges they face in their aim of achieving sustainable teacher learning and school improvement. The main research question of this study is: How do teachers in PLNs grow professionally?

\section{Theoretical framework}

\section{Teacher learning processes and outcomes}

Teacher learning is a socially and culturally situated process (Geijsel et al. 2009). To be able to enhance teacher learning and ultimately school improvement, it is important to first understand both the process of and conditions influencing teacher learning (Clarke and Hollingsworth 2002). The Interconnected Model (Clarke and Hollingsworth 2002) suggests that change occurs through the mediating processes of reflection and enactment in four distinct domains: the personal domain (individual teacher knowledge, beliefs and attitudes), the domain of practice (professional experimentation, applying the knowledge, skills and attitudes developed), the domain of consequence (salient outcomes), and the external domain (sources of information, stimulus or support). This model recognizes the complexity of professional growth through the identification of multiple growth pathways between the domains and identifies the mediating processes of reflection and enactment as the mechanisms by which change in one domain leads to change in another (Clarke and Hollingsworth 2002).

For teacher learning in PLNs, the change environment for teacher growth can be explained as follows. The external domain includes the PLN activities, influential factors (described below) and sources of information (e.g., external experts, extra materials provided by the PLN coach). The teachers' personal domain consists of their satisfaction, knowledge, skills and attitudes. In the domain of practice, the teachers apply these knowledge and skills in practice in their classroom and at their school. The domain of consequence refers to the products developed in the PLN and the conclusions that the teachers draw about the outcomes of their PLN. 


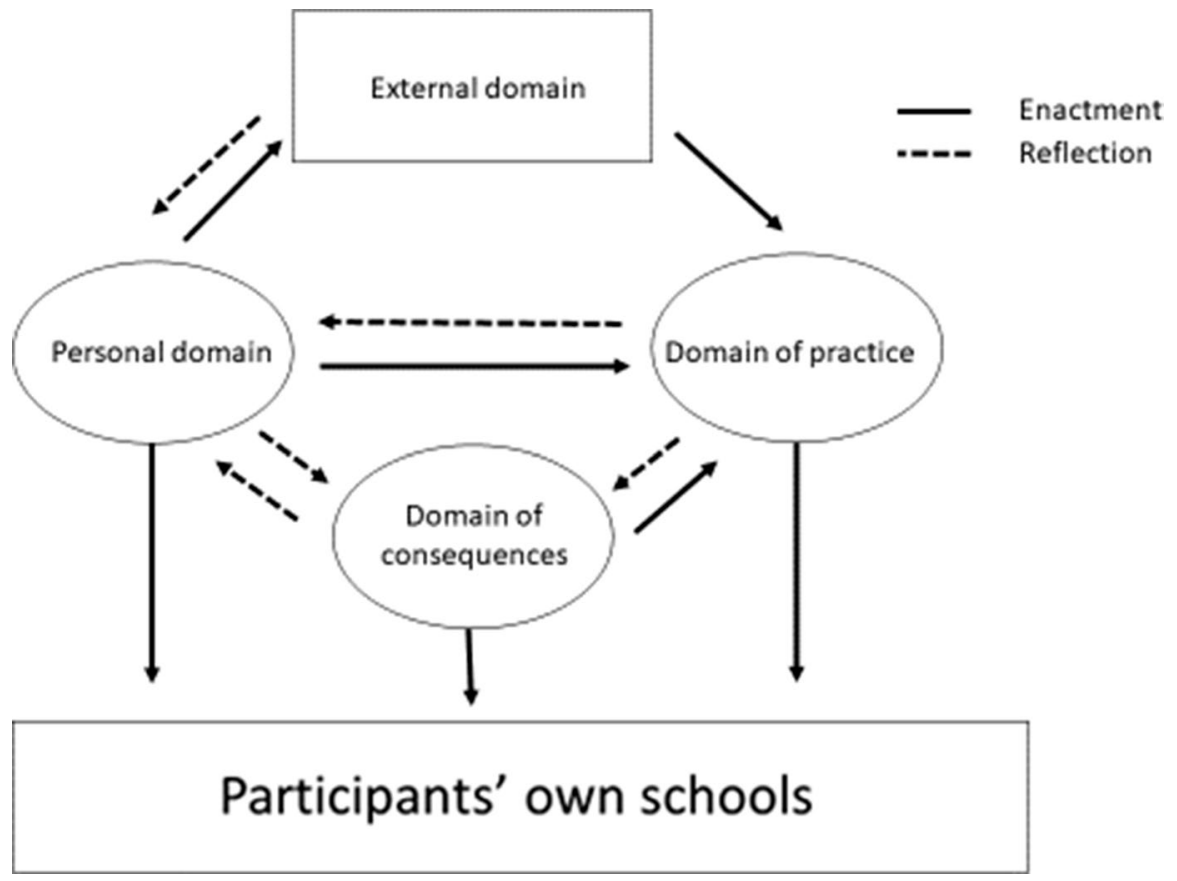

Fig. 1 Theory of action for PLNs (based on the interconnected model of professional growth (Clarke and Hollingsworth 2002, p. 951))

Enactment and reflection are the mediating processes responsible for teacher change. For example, the teachers participate in PLN activities (external domain). By reflecting on these activities, their knowledge and attitudes change (personal domain). The changed knowledge and attitudes can be applied by means of professional experimentation in the domain of practice (enactment). By experimenting in the classroom, the teachers might experience higher motivation of their students. By reflecting on the students' increased motivation that was experienced, the teachers' knowledge, skills and attitudes in the personal domain may grow further, as the knowledge base on what motivates students increases, for example.

For PLNs, teacher learning occurs in the PLN, with the purpose of transferring knowledge, skills, attitudes and products into the participants' own schools. To illustrate this, we adjusted the Interconnected model of Clarke and Hollingsworth (2002) as shown in Fig. 1.

We know from the literature that there are several factors within the different domains that contribute to these processes of enactment and reflection.

\section{Influencing factors}

A variety of personal, interpersonal, and conditional factors need to be taken into account before successful implementation of professional development activities 
can take place (Thurlings and Den Brok 2014). For this study, we identified the following characteristics from the literature.

Structured and guided activities that are related to practice. The extent to which the related activities are perceived by teachers to be part of a coherent program of teacher learning is an important feature of teachers' professional development (Garet et al. (2001). These activities should be related to goals and other activities, align with standards and assessments, and encourage communication with others (Garet et al. 2001). Handelzalts (2009) also emphasized that professional development activities need to focus, among other things, on providing examples of concrete classroom applications of the general ideas underlying change and expose teachers to actual practice rather than providing them with descriptions of practice.

A shared goal and focus on a concrete outcome. A shared goal concerns the extent to which teachers agree with the school's mission and its realization (Poortman and Brown 2018; Katz and Earl 2010; Lomos et al. 2011; Van Veen et al. 2010). Having a fundamental and clear organizational purpose is also critical to the success of PLCs (Andrews and Lewis 2004; Handelzalts 2009; Katz and Earl 2010). For PLNs, a shared goal and concrete focus refer to the shared sense of purpose among individual members (from different schools) of the PLN and how this coheres with the specific goals of the PLNs (Poortman and Brown 2018). For PLNs, the shared sense of purpose is complicated by the influence of different goals for participation that are set by the different schools (Poortman and Brown 2018).

Collective focus on student learning The focus on student learning reflects the teachers' focus on student success (Lomos et al. 2011). It helps to sustain commitment, creates peer pressure, and eases isolation (Bolam et al. 2005).

Individual prior knowledge and motivation Prior knowledge and motivation are recurring factors in individual and collective learning. Individual prior knowledge refers to the teacher's knowledge, skills and experiences prior to entering the PLN. Motivation refers to the process that initiates, guides, and maintains goal-oriented behaviors. According to Self-Determination Theory (SDT; Ryan and Deci 2000), a distinction can be made between intrinsic and extrinsic motivation. Intrinsically motivated teachers engage in behaviors for the pleasure or the satisfaction derived from performing a particular behavior. Behaviors by extrinsically motivated teachers are instrumental in nature and are not performed for the activity itself, but rather as a means to an end (Fernet et al. 2008). Prior knowledge, motivation, and also group variability influence individual learning, as well as the team's progress (Poortman and Brown 2018). Within a PLN, there is likely to be greater variability within the group, which may complicate the process of group learning.

Trust Especially when working with colleagues, engaging in collective learning can be tense. Unless they feel safe, teachers are unlikely to participate in classroom observation and feedback, mentoring partnerships, discussion about pedagogical issues, or curriculum innovation, for example. Therefore, colleagues' respect and trust are critical (Louis and Kruse 1995). Working and reflecting together can build trust and can strengthen relationships (Bryk et al. 1999), even when group members have different orientations and views (Lieberman and Grolnick 1996), which may be more likely for teachers from different schools. 
Collaboration and active participation According to Louis and Kruse (1995), collaboration refers to the (active) involvement of members in developmental activities with consequences for more than one person. This involvement includes more than the exchange of help, support, or assistance. The participants must be willing to open up their beliefs and practices to investigation and debate (Katz and Earl 2010), in which feelings of interdependence are central.

Active participation is important for effective collaboration (Voogt et al. 2011). For PLNs, it could be challenging to engage effectively with the different experiences, knowledge and expertise that are available to them in the network (Poortman and Brown 2018).

Reflective dialogue Reflective dialogue concerns conversations about educational issues that motivate teachers to discuss their teaching practices and to work together on how they can be improved. In these dialogues knowledge is exchanged and developed to enhance understanding and problem-solving (Mercer 2008). This reflection is assumed to lead to extensive and continuing conversations among teachers about, for example, curriculum, instruction and student development (Vescio et al. 2008).

Leadership The external coaches have an obvious leadership role for the PLNs described in this study. PLNs also facilitate distributed leadership in schools and across the network, with many people with and without formal positions of authority providing a range of leadership functions, such as leading particular initiatives, participating in collaborative groups, and sharing knowledge with others (Harris and Jones 2010; Katz and Earl 2010; Stoll et al. 2006). Thus, PLN members can be considered (informal) leaders themselves, even more so within their own school.

Stakeholder support: school (principal) and colleagues The quality and amount of external support are critical to accomplish change (Stoll et al. 2006). Much research in different domains has underlined the role of social support and social pressure in teachers' professional development. For PLNs, external support may be crucial, as the professional development activities take place with teachers from different schools, and not within the school together with their own colleagues, which might have consequences for their opportunities to reflect. In addition, the extent to which knowledge is shared within the teachers' own school might depend on the amount of external social support received.

Facilitation Stoll et al. (2006) reported several geographic and organizational factors that were shown to be influential for the creation and development of PLNs. First, the provision of time is important for attendance at their meetings (e.g., Louis and Kruse 1995; Van Veen et al. 2010). Second, size might play an important role in structuring a PLN's social dynamics to support greater face-to-face interaction and enhance communication within the PLN (Bryk et al. 1999). Third, location can be even more important for PLNs, as the geographic distances between participants are presumably greater, increasing travel costs and travel time. 


\section{Research questions}

Many factors need to be in place for PLNs to be successful. Little in-depth research is available about how PLNs work in terms of their key features, processes and outcomes (Chapman 2014; Katz and Earl 2010; Vescio et al. 2008). According to Clarke and Hollingsworth (2002, p. 947), in order to facilitate teachers' professional development, the process by which teachers grow professionally and the conditions that support and promote that growth need to be understood. The overall research question of this study is, therefore:

\section{How do teachers in PLNs grow professionally?}

More specifically, research question 1 is: What are the professional development outcomes for teachers participating in PLNs:

(a) In terms of the personal domain, regarding their satisfaction, knowledge, skills and attitudes related to PLN participation?

(b) In terms of the domain of practice, regarding application of knowledge, skills and attitudes?

(c) In terms of the domain of consequence, regarding products developed in the PLN?

Research question 2 is: What is the role of the external domain (sources of information, stimuli and support) in teacher professional growth during PLN participation?

(a) In terms of PLN organization and structure?

(b) In terms of PLN activities?

(c) In terms of the influential factors:

- Shared goal and focus on a concrete outcome of the PLN

- Collective focus on student learning of the PLN

- Individual prior knowledge and motivation of PLN participants

- Trust in the PLN

- Collaboration in the PLN

- Reflective dialogue in the PLN

- Leadership in the PLN (e.g. external coach) and by the school leader of the PLN members

- Stakeholder support from the school context

- Facilitation from the school context 


\section{Methods}

\section{Context of the study}

The context of the study was a 4-year pilot project (2013-2017) with 23 PLNs, each with 10-25 teachers from different secondary schools, facilitated by the Dutch Ministry of Education. In a national research project, the effects on and influential factors for teachers working in the PLNs were studied by researchers not involved in leading the PLNs. No specific guidelines for the content or structure of the regional PLNs were prescribed, other than that the PLN should consist of a mix of teachers from different schools who had graduated from higher professional and from university teacher education (i.e., different professional levels); that members should work on a specific approach or product as the outcome; that the PLN should have regular (monthly) meetings for at least 1 year; and that it should be guided by at least one teaching-subject expert in the area of research, curriculum design or didactic approach. Each PLN in the project was guided by one or two external coaches (teaching-subject experts) from a university ${ }^{1}$ (teacher training institute), and a university of applied sciences (teacher training institute), in the PLN region. The content and goal of the PLNs were determined by these facilitators (in cooperation with the participating teachers). We selected three PLNs for a qualitative case study to gain more in-depth insight into the process, influential factors and outcomes of these PLNs. One PLN focused on teachers' professional (research) attitude, one focused on the development of lesson material, and one focused on both: these represented the three main categories of PLN goals among all participating PLNs. The first had an evidence-based way of working as the main theme, the second had developing lesson material for 'students as researchers' as a theme, and the third focused on learning how to apply the Lesson Study approach. Selection of these PLNs was further based on having spread in region and teaching subject among the cases. Every case study PLN consisted of different teachers from different participating schools, and of different external coaches. Further details about the participating PLNs are presented in Table 1.

\section{Procedure}

A longitudinal qualitative case study was conducted with the selected PLNs. From the end of 2014 until the beginning of 2017, yearly interviews with a selection of PLN participants and their external coaches were conducted to collect data (three measurement points). Complementary to the case study interviews, we collected information about influential factors from a log that was completed by the external coaches of the PLNs after each PLN meeting. We used yearly (nonparticipant) observations of a PLN meeting to be able to refer to examples of

\footnotetext{
1 Student teachers graduating from a university program can teach all levels of secondary education; student teachers graduating from a university of applied sciences can teach in the first 3 years of general and pre-university secondary education, as well as all 4 years of pre-vocational education.
} 


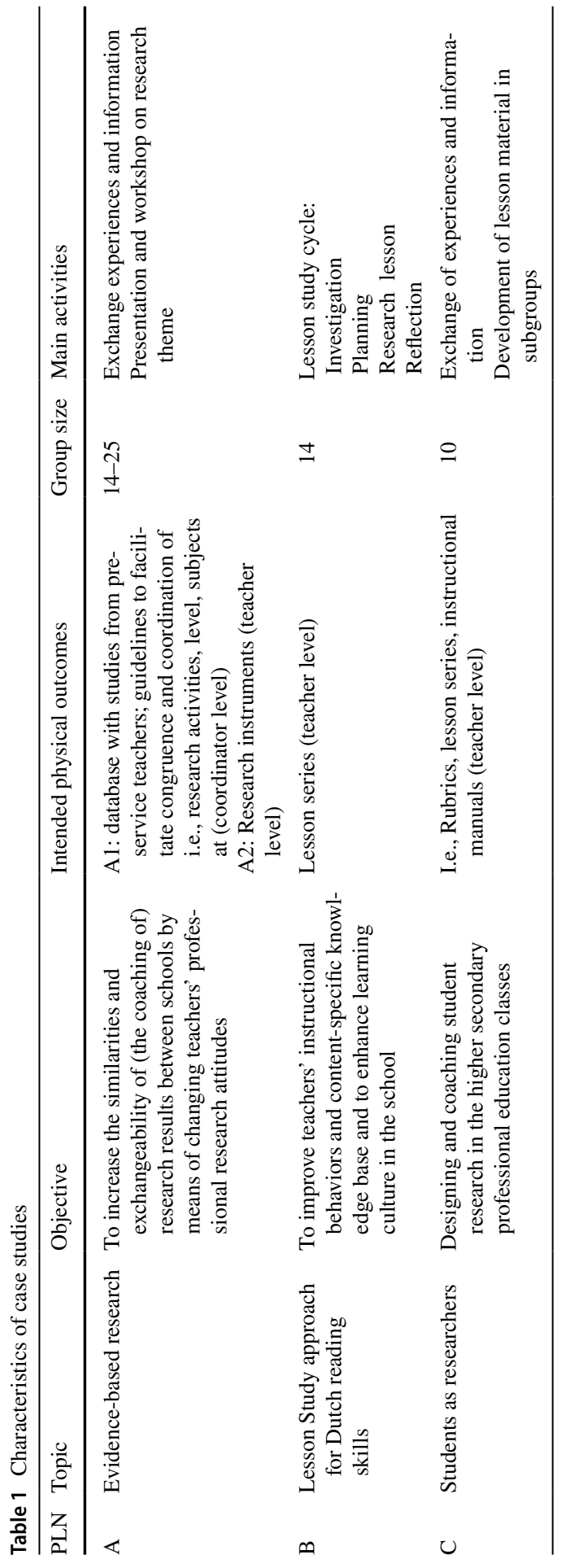


activities and context to respondents in the interviews. We promoted the quality of this study by applying data triangulation of the interviews by involving different teacher participants, and the coach; and method triangulation by also using coach logs, and observations (Denzin 1978). Moreover, investigator triangulation was applied specifically in the analysis stage regarding the coding procedure, and in general by the three authors collaboratively working on data collection and interpretation. For each PLN, the same procedure was applied. The data collection procedure was approved by the ethical review committee of the University.

\section{Respondents}

For each of the three PLNs, the external coaches were respondents regarding their coach logs. Per case, we also interviewed one coach and three teachers yearly. Within the PLNs, respondents were recruited for the interviews on a voluntary basis. At the end of the observations preceding the interview period, we asked which teachers would be willing to be interviewed within a few weeks after the observation, taking into account who had already been interviewed before. The coaches aligned their availability with each other and alternated their participation in the interviews for the different years.

For case A, we interviewed eight different teachers, and two external coaches; for case B seven different teachers and two external coaches; and for case $\mathrm{C}$ nine different teachers and three external coaches, throughout the entire study.

\section{Instruments}

\section{Interviews with external coaches and teacher participants}

Data about the influential factors and PLN outcomes were collected by means of audiotaped case study interviews with teachers and the external coach. The interviews were $30 \mathrm{~min}$ long on average. The interviews were conducted by the researchers using an interview scheme. Interviews were held following the observation of the PLN meeting, to be able to also ask about specific PLN meeting activities in the interviews. Open-ended questions based on the elements of the theoretical framework regarding perceptions of the factors assumed to contribute to professional development, as well as perceptions of the outcomes, were asked of both the teachers and external coaches. Concerning outcomes, we asked, for example: In what way does the PLN add to your knowledge and skills? and To what extent do you apply what is explained, discussed or constructed in the PLN? In what way? Concerning factors, we asked, for example: In what way do teachers collaborate in the PLN? and To what extent and in what way do you have contact with your principal/colleagues/school board about the content of the PLN? 


\section{External coaches' logs}

The logs served to follow gradual developments over time, from meeting to meeting. Beyond providing information about several organizational aspects of the meeting (time investment, frequency and number of participants), the log focused on: the purpose and activities of the meeting and what it produced; what went well during the meeting and what could be improved; how collaboration took place; what was agreed upon for the next meeting; and any other reflections by the external coach. A question was also included regarding the results or products of each meeting.

\section{Observations}

For each of the cases we attended one PLN meeting per year, for which purpose an observation form was used, to obtain information about PLN meetings and their actual activities. The observation form contained items regarding the number of participants, the amount of time spent on the meeting, the specific goal of the meeting, the activities, the products, the collaboration, an evaluation and appointments made for the next meeting. Additional remarks could also be made on the observation form. The researchers only took notes and did not ask questions during the meetings.

\section{Data analysis}

We transcribed the interview data verbatim from the audiorecordings. We developed a coding scheme based on the theoretical framework for both the outcomes for teachers participating in PLNs (e.g., personal domain-satisfaction; domain of consequence-products) and the role of the external domain (processes and conditions, e.g., activities; individual prior knowledge, motivation, and leadership). This coding scheme is presented in Table 2.

We used the program ATLAS.ti for coding and comparing the transcripts of the interviews, external coaches' logs and observations from different respondents, within and across cases. We first pilot-coded and discussed part of the data to test the coding scheme. Definitions in the coding scheme, such as facilitation, were adjusted based on discussions about the coding scheme among the researchers. Three researchers then independently coded approximately the same $10 \%$ of the transcripts. The inter-rater agreement was substantial, with a Cohen's Kappa of 0.65 (Landis and Koch 1977). Subsequently, one of the researchers coded and analyzed the remainder of the data. Findings for the interviews, $\operatorname{logs}$ and observation notes were summarized in a within-case table (per code category) first. For the cross-case analysis, the tables per case were compared and summarized in a cross-case synthesis. The temporal nature of the data was addressed where relevant: when changes occurred during the years this was noted in the findings (e.g. 'in the first year...'; 'in the final year'). 
Table 2 Coding scheme

\begin{tabular}{|c|c|}
\hline Codes & Indicators \\
\hline \multicolumn{2}{|l|}{ Personal domain } \\
\hline Satisfaction & $\begin{array}{l}\text { Teachers' (individual) satisfaction with their PLN partici- } \\
\text { pation (e.g., coaching, organization, content, materials, } \\
\text { progress) }\end{array}$ \\
\hline Knowledge, skills and attitude & $\begin{array}{l}\text { PLN-related and reported knowledge/insights, skills and/or } \\
\text { attitude of (individual) teachers }\end{array}$ \\
\hline
\end{tabular}

\section{Domain of practice}

Application

Actual application of developed knowledge, skills and attitude and the developed approach or product by PLNteachers in their daily practice (e.g., applying lesson material, performing research)

\section{Domain of consequence}

PLN-specific goals

Achieved goal with regard to teachers' professional attitude or the design and development of new lesson material (e.g., by means of Lesson Study)

\section{External domain}

PLN activities

Activities within and outside PLN meetings (e.g., presentations, assignments)

Goal and focus

Focus on student learning

(Shared) goal and focus of the PLN (e.g., general subject or theme)

Prior knowledge, motivation, personal goals

Shared focus of the PLN members on student learning

The teachers' individual prior knowledge about the PLN's subject/theme, motivation for PLN participation, and personal goals of individual members

Trust

Collaboration and active participation

Trust among PLN members and the atmosphere within the PLN

Collaboration within the PLN and teachers' active participation (including presence)

Reflective dialogue

Discussions that take place within and outside PLN meetings

Leadership school leader

Leadership within PLN by school leader

Leadership external coach

Leadership within PLN by external coach

Leadership teachers

Support

Leadership within PLN by teachers (distributed leadership)

Schools and colleagues form a supportive environment for teachers with regard to their PLN participation and opportunities for applying the acquired knowledge, skills and products in practice (e.g., interest, mental support)

Facilitation

PLN facilitation from the school/external coaches (e.g., time, school time schedule, frequency and duration of meetings)

In the findings we have indicated the sources (e.g. interview teachers or log coach) and we have explicitly indicated where findings were confirmed, complemented or contradicted among different sources, illustrated with respondent 
citations. The conclusions are based on a comparison among the cases of the summary per theoretical framework element per case.

\section{Results}

In this section we describe the results in terms of outcomes (RQ1) and role of the external domain (RQ2, processes and conditions) per case. To provide a context, first the elements of the organization and structure of the PLN in the external domain (RQ2) are described. Then we look into their activities (RQ2). Subsequently, we describe the outcomes in terms of the personal domain, the domain of practice and the domain of consequences (RQ1). To conclude each case description, we look into the role of the external domain in terms of influential factors, such as leadership and stakeholder support (RQ2).

\section{Results PLN A: We do not say, 'let's do this together'}

\section{External domain - context}

Organization and structure PLN A is focused on participants who coach and assess pre-service teachers in their practice-based research at (internship) schools. Teacher professional development in research methods was addressed, as well as the stimulation of practice-based research within the schools-both by the pre-service teachers and their coaches (PLN participants). The objective of this PLN was to also increase the quality of the collaboration between school boards, and the teacher training universities in the southern part of the Netherlands. Coordination and coaching at the school level should therefore become better informed and executed by means of knowledge sharing at the level of practice-based research to target school development and improvement of education. In PLN A, there was a core group of 14 participants from different secondary schools in the region ('PLN A1'). Their focus was on exchanging information and reflection. In this PLN the organization and adaptation of (the coaching of) research activities within internship schools, both by pre-service teachers and in the schools in general, was discussed. Additionally, interested colleagues of this core group were invited to the content-specific meetings ('PLN A2'). This 'PLN A2' focused on developing research skills and subject-specific practice-based research themes by participants. Figure 2 visualizes the structure of the relation between the schools and both PLNs. PLNs A1 and A2 alternated meeting monthly. PLN A (1 and 2) was coached by three external coaches: one from a university (teacher training institute), one from a university of applied sciences (teacher training institute), and one from the internship school network.

Activities In PLN A2, participants worked on a particular theme related to research skills (i.e., the development of questionnaires, statistical analysis in software packages, metacognitive skills, etc.), often independently of each other. Participants were asked to prepare for the meeting by studying literature, after which they were assigned to subgroups in the meetings to stimulate discussion. Regularly, 

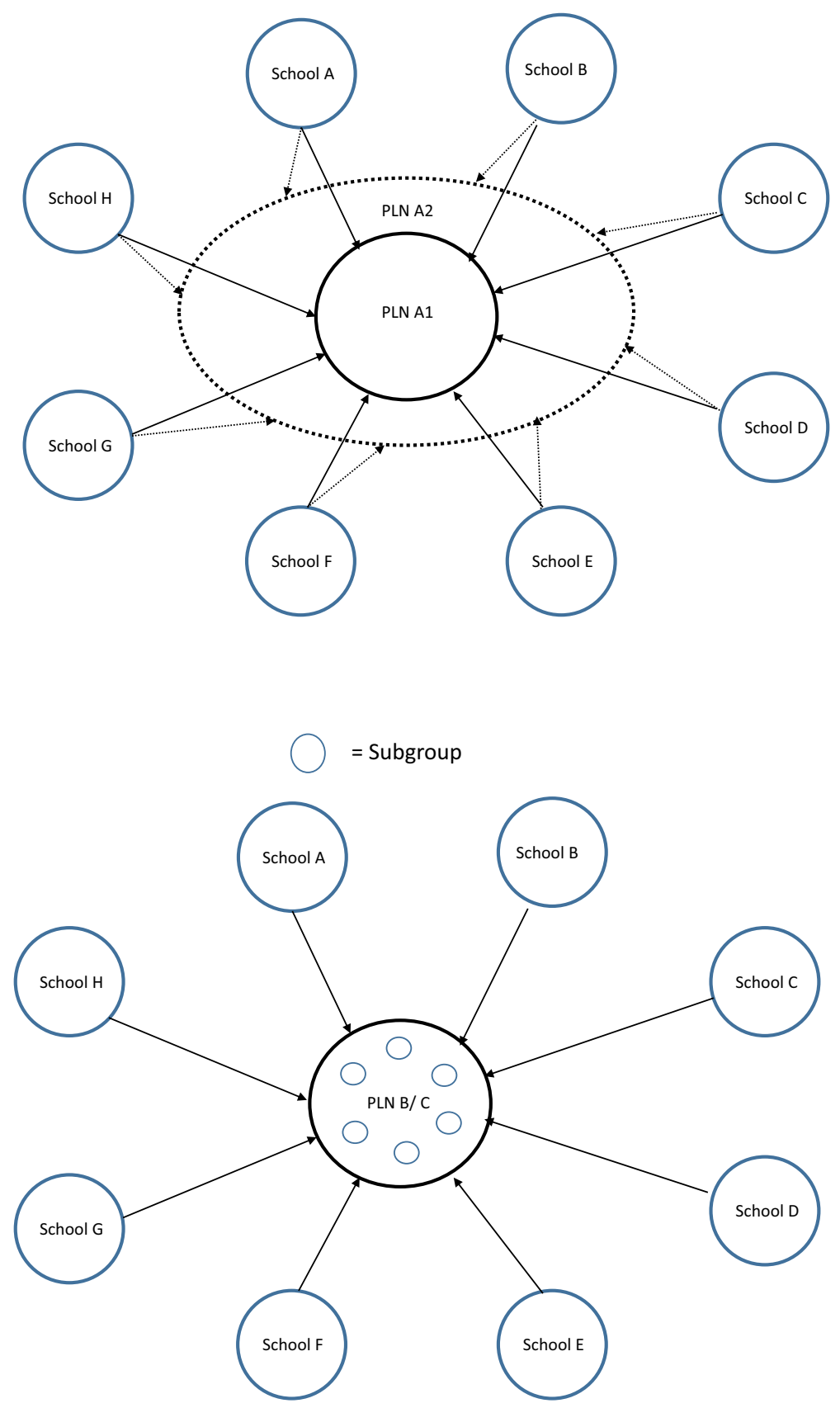

Fig. 2 Visualization of the structure of the relation between the schools and PLN A1 and A2 
guest speakers were invited, or the external coach of the PLN gave a content-specific presentation for the first part of the meeting. In the second part of the meeting, participants worked on the theme, mostly in groups. In PLN A1, the focus was on reflection about the PLN A2 meetings and exchange of information, to increase the similarities and transferability of (the coaching of pre-service teachers and) research results between schools. In PLN A1, participants also worked on a database with studies from pre-service teachers, to structure a line of research within the school system. Meetings often started with the exchange of information between schools. Then they reflected on the previous A2 meeting. Also, themes for the next A2 meetings were discussed.

\section{Personal domain}

Satisfaction In general, teacher respondents reported experiencing PLN A as useful and important; for example: "I think it is a great development. It has finally come this far that it gets more content, causing the school board, and the school...to be more inclined to put more energy into it." Teachers liked the intended goal of the PLN to share their research experiences in order to decrease overlap and inconsistency in their way of working. They valued the division between A1 (reflection) and A2 (themes). The content and experiences of A2 were evaluated in A1, which teachers valued as being professional and informative. The external coach also reported that the participants were enthusiastic. However, multiple teachers reported a lack of interaction and depth of content, as A1 was mainly about exchanging experiences and A2 was more superficial because of the different themes and participants. Also, during the final year, teachers still experienced that there was no coherence between themes in A2 meetings, and they felt there was repetition of subjects. Two teachers who had participated from the beginning were therefore still not fully satisfied with the progress of the PLN at the end. One of them reported:

I was expecting that more would happen within the schools. That new projects would start. That it (the PLN) would be a kind of catalyst for other things. But that is not the case (...) They (the teachers) learn and they tell about it, and then it stops.

Knowledge, skills and attitudes The shared aspect of knowledge within this PLN was knowledge about the methods, routines and processes of working regarding research in different schools. This led to inspiration and ideas. One teacher stated: "There are multiple roads to Rome, and in our teacher training we learned some, but maybe people have better ideas." Depending on their prior knowledge, some teachers reported that the PLN let them refresh their existing knowledge about research skills but they gained no new skills, where others stated that it added to their current knowledge base. Also, one teacher reported a deeper understanding of coaching students' (i.e. pre-service teachers') research and the acquisition of skills, such as questionnaire construction. Furthermore, teachers reported a change in their professional attitude. They developed a different view of the quality and requirements of pre-service teachers' theses. For example, one teacher realized by means of a PLN 
A1 meeting that she had asked too much from her students. Others reported having become more critical about their own educational practice. Lastly, one teacher reported that he had become more aware of what he can do within his own school to achieve research products more similar to those of students within the network of schools.

The external coach underlined the findings reported by the different teachers. She reported that many research skills were gained (e.g., writing a research paper, APA guidelines, citing, analyses with Excel, etc.), and also that the professional attitude had changed. Teachers coaching pre-service teachers had become more aware of what role they have within the school and the collaboration of their internship schools and the teacher training institutes, considering the diversity of students' research within the network. Although she reported enthusiasm among the participants, however, she missed the presence of a deeper level of content. She reported a lack of interaction: participants did not work together on research proposals, for example, while there were many possibilities of doing so. This meant that teachers did not construct knowledge together.

\section{Domain of practice}

All teachers reported in the interviews that they applied the acquired knowledge and skills in their own practice, but only when the appropriate situation came along. One teacher described concerning this point that he took the information from the PLN into account in general, but that the application of details was hard, as school conditions (e.g., time) did not allow for it. Two teachers reported a specific example of application in that they were part of a research group/PLN within their own school, in which they applied the knowledge and skills from the PLN. They shared knowledge about content-specific themes, but also reported on the progress of the A1 meetings in which research experiences were shared between schools and participants tried to reach concordance on the subjects and the required quality of preservice teachers' research.

The external coach reported that teachers applied the knowledge and skills when they supervised their students' research and some applied them in their own research.

\section{Domain of consequence}

No physical products were reported. The observations showed that teachers were not actually constructing products together. They were performing assignments on the meetings' subject to learn, and to be able to apply and disseminate this knowledge in practice. One teacher reported a possible indirect effect of the PLN on his students. He indicated that examples he gave to students about his own research appealed to his students, and consequently, the PLN influenced the students' research in this sense. Other teachers and the external coach reported no results at the student or school level. 


\section{External domain - factors}

Shared goal and focus on a concrete outcome The subject of PLN A was 'evidencebased work' among internship school teachers, according to the title. In the first year of the PLN, however, teachers indicated that they were not sure about the goals of their PLN colleagues in A2. In the second year, teachers were still not sure, or indicated that there was no shared goal. One teacher stated: "I am not sure about it. It is literally, you come in, you participate, and then you take off." In the final year of the study, teachers indicated that the goal in A1 was clear; however, in A2 the only common theme was to exchange what research-related activities took place within their schools. The external coach during the first year found that the participants strived for the same goal; however, the (other) external coach during the last 2 years was less sure. The group varied too much, as did the subjects of the meetings (e.g., constructing a survey, qualitative research), to be able to determine that the goal was shared among participants. Findings from the observations confirmed this conclusion. Many participants did not know each other, and had to introduce themselves at the start of the meeting.

Collective focus on student learning The external coach and the teachers mentioned that they used their knowledge and skills to improve the coaching of students' research by the participating teachers.

Individual prior knowledge and motivation Prior knowledge and background were very different among participants. Some had a Ph.D., while others were only involved in research in relation to guiding students' theses. Some participated to stay up-to-date, others came to learn and gain research skills. Some were intrinsically interested in the subjects and the network, others had been asked by the school board to participate in relation to the guidance of students' theses.

The external coach reported that the differences in background did not limit the motivation to attend the meetings. Participants complemented one another. She stated:

There are actually different stakeholders within the PLN and everybody has their own interest. I notice that the participants who guide student teachers have the need for supporting skills. But you also notice with the educators from teacher education that there is a lack of consistency across their interests. Also, they do not feel they have to learn new things, but they want to create a kind of certainty, self-efficacy.

Trust The participants reported a good atmosphere throughout the years. One teacher stated in the first year that probably teachers should first get to know each other better in order to be willing to share more knowledge. The external coach described the atmosphere as positive, with no barriers to contacting each other or to saying certain things. However, it was formal, and superficial.

Collaboration In general, collaboration between schools was restricted to the meetings, although participants were sincerely interested in each other's schools. Findings from the observations showed that not every participant collaborated actively during the meetings. Even when participants were asked to discuss the assignments in groups, there were still teachers who did not participate in this 
collaboration and completed the assignment individually. One teacher reported: "There is no collaboration. We do not say, let's do this together." Participants regretted the lack of collaboration, but as one teacher indicated in the second year, collaboration was not always possible, for example, because of a lack of time and facilitation. One teacher reported seeking actively for collaboration. Whenever he heard something interesting in the PLN, he contacted that person outside the PLN meetings to get more information or to collaborate. The external coach reported, however, that the collaboration within meetings was good: they worked on exercises together and were actively involved. However, outside meetings there was little collaboration. She stated:

They speak of many ways to collaborate more closely with each other, but until now this has not happened yet. Missed opportunities...I think that two or three participants are externally focused on collaboration. The others are more like 'I think it is good enough to attend the meetings, and talk a little about that within the school' and that is it.... But to say new knowledge is created... I expected more.

In the final year, one teacher reported that another participant had started to collect all of the education research at the schools in the network to establish a common structure and to be able to improve alignment within the network. Also, one teacher stated that the institution for higher education/the project managers had matched schools together, in which one was the 'leader', and the other the 'follower'. However, that did not work for their school; it was not a good match.

Reflective dialogue In general, teachers stated that there were not a lot of in-depth discussions. One teacher described that the discussion consisted of exchange of experiences, tips and remarks. This finding was confirmed in the observations. However, participants did give each other critical feedback. One teacher stated: "People are very careful. You notice it in the small groups. But in the whole group there are one or two or three remarks and then the external coach puts it all together again." A teacher stated in the final year that they did not get further because of the lack of a deeper level of discussion:

How do you get to the next step, and how do you get insight in your results? And what is the next step from that point on? And how do you handle that to decide... how do we get to a better evaluation system?

Additionally, he felt that the guidance of the discussions by the coaches was not effective for this purpose.

The external coach reported that there were discussions, but that there was no construction of knowledge:

During meetings everybody acts well-behaved. But more like, this is the agenda, thus, that is what we do. Or, this is an exercise, and then we do these steps, and afterwards we say, this was nice. Great. And then I think: what is next? (...) There has to come a moment that you say, what is in it for me? How can I apply this? What is the next step for me? 
Leadership The external coaches had two roles. First, they served as PLN coordinators. Teachers reported that the external coaches managed the content and structure of the PLN meetings, arranging the location, sending invitations and agendas for the meetings and making materials available. This role was also observed by the researchers. In the second year, teachers indicated that external coaches anticipated the needs of the participants more. Second, they served as coaches and invited guest speakers when expert knowledge was needed. However, the participants did not explicitly mention external coaches in the role of coach. Moreover, one teacher experienced little support from the external coaches, and only in the form of coordinating the meetings. Additionally, two teachers indicated that the difference between PLNs A1 and A2 was not clear enough for them.

The external coaches reported that their objective was to deliver tools to stimulate teachers to improve their coaching skills for students' research. Their main role was that of coordinator. Sometimes they could fulfill the expert role, but they also invited guest speakers. They intended to set up interactive meetings: to give content-specific knowledge, but also to challenge and to stimulate participating teachers to give input themselves. In the second year, the external coach described finding it difficult to give content-specific input for the meetings, as participants did not show ownership of the PLN, feeling that "It is not our PLN, it is a project in which I (the participant) am involved." She prepared the meetings and asked teachers to do the same, so they could collaborate with regard to the subject during the meetings but that is not what was happening. In the final year the coaches noticed that the coherence of the meetings (combination of presentation and workshop) decreased and it became harder to involve schools. They tried to solve this by inviting more skilled students and researchers as guest speakers. Additionally, the external coach reported that they had to make an effort to encourage teachers to work on the subject outside their studentrelated coaching activities, for example, by doing their own research.

Stakeholder support Multiple teachers described the PLN as part of a bigger whole within their own school. They had a workgroup or kind of PLN at their own school discussing the same subjects. Information from the PLN was meant to be shared in these groups. These teachers were allowed time to work on research activities, and used the PLN to give content to that time. When relevant to their colleagues, they invited them to join the PLN. However, this differed per school. For example, a teacher reported:

Discussions within the PLN are valuable, however, I am doubtful about the experiences I hear from other schools: is that applicable for me? Can I take that within my school? And then I come to the answer that I cannot. I cannot get that implemented in my own school, as the organization does not desire that, or we cannot get it together. So the structure of the organization is entirely different, and then it actually stops again.

Others reported that they shared important information in an informal way with colleagues, and that the PLN was a subject of performance interviews. Some came to the PLN with colleagues, and one teacher reported that his principal was participating in the same PLN. 
The external coach added that information was shared within schools, but they did not construct knowledge with other schools: "Ideas are brought back to the school, and then it stops." The "upload' of information from the schools into the PLN was also lacking.

Facilitation The teachers from the first year were not satisfied with the support from the school. They were allocated $20 \mathrm{~h}$ per month for three persons, excluding traveling time, to attend and prepare for the PLN. In the second year the teachers were satisfied: two teachers had an afternoon free in their schedule once a week, and the other teacher interviewed received $200 \mathrm{~h}$ per year to attend and prepare for the PLN. In the final year, teachers indicated that the PLN was part of their coaching task with their students (for students working on their thesis). One teacher stated that the amount of time for research activities had decreased compared to the previous year. The external coach reported that facilitation is crucial, as teachers have a high workload. Therefore, external coaches kept attendance lists: "They (the schools) know, they only get the money for the attendance of the participants, so they are aware of that." Facilitation differed a lot between teachers: some were free in their schedule, others had to catch up by giving lessons later.

\section{Results PLN B: This is a way in which everybody is made responsible and gets involved}

\section{External domain - context}

Organization and structure In this PLN about reading skills in Dutch as a first language, the Lesson Study approach was applied. Lesson Study is a specific approach for teacher learning that originated from Japan and was more recently introduced in the Netherlands. In Lesson Study, teachers collaboratively plan a research lesson, observe this lesson live, collect data and analyze these data together to improve students' learning (Fernandez and Chokshi 2002). A first objective of the PLN was to improve teachers' instructional behaviors, in particular the more complex behaviors such as activating students and differentiating between them. Secondly, the PLN had a content-specific topic, reading skills and the development of effective instructional resources. Thirdly, enhancing the learning cultures in the respective schools by introducing Lesson Study with the PLN members as future Lesson Study facilitators was another important aim of the PLN. This was done by gradually increasing feelings of ownership and responsibility among the participants. In cycle 5 (later on in the project), for example, the Lesson Study was prepared in the PLN context and the research lessons were given and observed by colleagues at the schools, and in cycle 6 the Lesson Study will be carried out by in-school Lesson Study teams, led by the PLN participant as Lesson Study facilitator (e.g., Prenger et al. 2017).

The PLN was coached by two subject pedagogy external coaches for Dutch as a first language from teacher education institutes affiliated with two regional universities. The PLN consisted of 14 teachers from secondary schools spread throughout the north of the Netherlands. The external coaches and the overall project manager 
formed the PLN project group steering the PLN. The directors of both teacher education institutes and two school leaders formed the advisory board.

Activities The method used in this PLN consisted of six different cycles, two per year. During each cycle, the participants were divided into subgroups of three and four participants, hereafter referred to as Lesson Study teams. After the second cycle, subgroups were reorganized into more heterogeneous groups to increase applicability of the developed output at multiple student levels. The Lesson Study teams met for two or three investigation and planning meetings in the context of their own PLN. Teachers were introduced in a new topic of their content area in relation to the learning and teaching of this topic. Subsequently, they developed the research lesson, wrote down the instructional plan, including goals for student learning and development, anticipated student thinking and data collection points. The research lessons took place in the respective schools. One of the team members conducted the research lesson, and the other team members plus one of the external coaches or the overall project manager observed and collected data during a live research lesson. The teachers visited each other's schools twice per cycle for observing the research lessons in the original and the adapted version, and for the postlesson discussion (reflection). Each cycle was concluded with an evaluation and reflection meeting in the context of the PLN, where the Lesson Study teams shared and discussed data from the research lesson, and drew implications for lesson redesign, for teaching-learning more broadly, and for the understanding of students and subject matter. Several times per year, meetings were organized for school leaders of the schools involved to inform them about Lesson Study activities and progress. For the colleagues and school management involved, each year a closing conference was organized, at which the Lesson Study teams presented their lesson studies and their lessons learned.

\section{Personal domain}

Satisfaction In general, teachers felt that they learned from the PLN. They valued the research lessons, reflection and planning in particular as learning activities. The investigation and planning parts were less feasible for them, however.

Teachers enjoyed working on the core aspect of teaching: developing lessons. They were satisfied about the goal-oriented nature of Lesson Study. One teacher described after the second year: "It is very pleasant to prepare the same lesson with multiple colleagues. And that you first discuss, what do we actually want, what is the goal? And that you work from that goal." One teacher indicated that she was very satisfied about the student-oriented way of working and that she valued the constructive character of implementing PLNs within the school.

However, teachers were critical about the manual they used for Lesson Study, and especially the investigation part of the method. This was "too structured and generating extra work." Also, some found it annoying to keep being corrected by the external coaches, and regarded the approach as akin to going back to school again. However, these teachers acknowledged the necessity of this approach for the learning experience. 
It automatically goes from micro to macro, as you are working on a lesson which is adjusted over and over again. You see how it impacts the students. And everything you learn there (in the PLN), can be applied to your own teacher practice.

However, in the last year, teachers reported that they felt it had been valuable, but also very intensive. One teacher described: "I think it is a very good method. But well, it has been very intensive. I think that it is OK that it lasts for 2 years (and no longer)." Additionally, another teacher reported that she had guided three lesson study PLNs within her own school now, which had been very time-consuming, and stated that facilitation is important.

According to the external coaches, participants thought it was valuable to collaboratively prepare a lesson. This led to feelings of ownership and relevance among teachers: "Then the evaluation focuses on what the students learned, instead of what the teachers did."

Knowledge, skills and attitude Participants reported they had learned about students and student thinking, and about didactics in general, and that the PLN had raised their awareness about teaching in general and their contact with students. Teachers became able to make choices about which didactic forms belonged to the set goals, and to observe students. They felt that their teaching was now more theory-based and less subjective. Also, they experienced development in their professional attitude. Furthermore, the visits at each other's schools brought about a broader view on education in general. Personal factors also changed following Lesson Study participation. Teachers became more confident in their teaching by focusing on students' learning: "It really strengthened my confidence, that you have time to develop lessons with other teachers.' And 'By observing students, I gained confidence that the lessons work. Normally, when you teach, you do not always see what is happening."

Additionally, teachers described: "I learned more about collaboration, even if it takes more time, it adds value to search together for texts and to decide together, instead of doing it individually." Teachers valued the new contacts and the exchange of experiences, as it gave them energy and new ideas to bring back to their own teaching practice. Teachers found that the PLN led to greater clarity among students: "We give students more clarity, as we handle things in the same way now.... Our role as a teacher is less prominent now, more the students."

Concerning the professional attitude of teachers, the external coach added a critical note. Some teachers did not seem to be open to 'other things', and did not show a research-based attitude.

\section{Domain of practice}

For some teachers, the PLN changed their teaching practice:

"My classes are more active now, because I increased the interaction," and "I have more focus on the preparation of the lessons, I make sure now that I have 
prepared the PowerPoint presentation including the presentation of the goals, and what we are going to do, what exactly is the purpose of the lesson."

Not all teachers applied the products in practice and questioned the feasibility of the implementation of Lesson Study in their own school for the long term. On the other hand, teachers did apply the developed lesson series within their own school. They also applied the Lesson Study approach in other classes. One teacher reported that her colleagues were applying the lesson series, too. The external coach confirmed that application of materials was part of Lesson Study.

\section{Domain of consequence}

Physical outputs were the newly developed lesson series, lesson materials and a manual for teachers, but also refinement of research about practice, research instruments, improved lessons and improved student results. The observations confirmed that teachers were working on lesson series and materials during the meetings. However, teachers and external coaches both reported that they did not actually establish effects on students results by means of an experimental design. One teacher did report that she thought there were effects at the student level, as her own attitude towards practice had changed. On the other hand, another teacher reported that students were not aware of the changes that had taken place in the way of teaching, or the lesson series, which implies that it is not clear if the PLN led to improvements in student results.

\section{External domain - factors}

Shared goal and focus on a concrete outcome The subject of PLN B was the Lesson Study approach for Dutch reading skills, according to its title. The teachers described that at the beginning, the objective of bringing the Lesson Study method back to their own schools was not clear to them. However, after a few meetings, this lack of clarity was resolved and the goal was shared among participants. Ideas, desires and interests differed within the subgroups. Subgroups were adjusted for these diversities to increase the degree to which there was a shared goal.

Collective focus on student learning The focus of the Lesson Study approach was the improvement of student achievement results. Teachers highly valued this focus, which was the reason and motivation to participate for most teachers. The external coach described how the teachers' focus shifted from their own teaching to how students learn and how teachers can make this visible.

Individual prior knowledge and motivation The motivation for participation differed between teachers. Some were interested in the subject, and liked developing themselves professionally; others were asked by their school board to participate. Some teachers were enthusiastic about participation, but became discouraged by hearing about the effort they were asked to invest:

When I heard that we had to make lesson series, that were going to be published and had to be given by other teachers, and how many that was, I really 
got scared. I thought it would take a lot more time than I am spending now....

It is not as bad as I thought.

One of the external coaches observed an increased motivation after the third cycle in the second year, partly because the composition of the subgroups had changed. She perceived from participants that the motivation to participate was the focus on student learning and the fact that it was a professional learning network: collaboration between teachers from different schools. However, a research-based attitude was lacking among multiple participants, which made the external coach wonder if the PLN would have been more effective if that had been a criterion for participation. Nevertheless, the coach also stated: "We are doing this for three years now, so you can imagine that people may get less motivated, as they have seen it by now. But that is actually not the case. Every cycle is interesting and good for everybody."

Trust All teachers valued the atmosphere as pleasant and good, and experienced mutual trust and respect. Multiple teachers reported that they still had contact by social media: "You are working intensively together for a short time period. That creates a certain bond together."

The external coach reported:

They have a lot of fun. I think that this partly has to do with the fact that you have some sort of shared ownership by means of Lesson Study. You design a lesson together. This means....that teachers judge the lessons as such, instead of the teacher teaching these lessons. I think that gives a feeling of safety by which teachers feel free and comfortable.

Collaboration In general, collaboration was perceived positively. The observations showed that teachers were working in subgroups during the meetings. Teachers experienced collaboration differently within the Lesson Study teams. One teacher liked the variation in vision within the team, as it generated new ideas. Another teacher was not satisfied with the collaboration in her subgroup. This teacher thought the motivation for PLN participation (the teacher's own initiative versus the school leader's initiative) impacted the collaboration, as did the teacher's vision of education and personal characteristics. This led to ineffective discussions in the subgroup. Most teachers, however, indicated that they worked hard in the PLN, as did the other members within their subgroup. They regularly met outside of meetings, physically as well as via social media. One teacher indicated that good collaboration is a process, which needs time to work. The core aspects of Lesson Study (to deliver research lessons at their own schools), according to one teacher, automatically demanded that each member work hard. The external coach reported that teachers worked together on how to design lessons, prepared lessons together, divided tasks, had contact in group apps, told each other about interesting articles or programs and exchanged experiences: "I do think that this is a way in which everybody is made responsible and gets involved with the design and performance of the lessons."

Reflective dialogue The teachers reported that the number of discussions and the depth of discussions depended on the subgroup they were in. Some teachers reported that they had discussions because of the entirely different visions on lesson design held by a couple of teachers. Another teacher indicated that the discussions 
in her subgroup were interesting because the visions of teachers were close to each other. The external coach pointed out that reflections on the research lessons were part of the Lesson Study cycle.

Leadership In this PLN, coaches fulfilled three roles. First, they served as coordinators, and took care of organization, together with the project manager, who took care of contacts with the schools and evaluated the group's progress with the external coaches. Second, they served as experts in their role as external coaches. Third, they coached the participants by closely monitoring and reflecting on their progress, which was part of the Lesson Study cycle. All three roles were also observed by the researchers: content-specific questions from the teachers were answered, and in one of the observed meetings the external coach reflected with one subgroup on the process. The external coaches attended most research lessons at the schools to discuss and reflect on the lessons with the participants. All teachers experienced pleasant collaboration with the external coaches and were satisfied with the coaching: "They are present, but not obtrusive. They adjust, ask questions, let us think, that is important." Teachers felt the external coaches were goal-oriented, flexible and enthusiastic, which they valued positively. The external coaches were open-minded and were not afraid to discuss negative aspects during the process. One teacher described: "The external coach is very capable, and knows what critical questions to ask, which improves the quality of the research lessons." However, teachers did not experience a lot of content-specific input from the external coaches in the first year. In the second year, the set framework by the external coaches was valued less positively compared to the first two cycles. Measures taken in the third cycle (second year) were to accomplish another goal of the Lesson Study project team: to train participants to become Lesson Study facilitators in their own school environment. As already described, the external coaches decreased their Lesson Study process-specific guidance in this cycle. Some teachers regretted this change, as the vision of the PLN was consequently followed less strictly. However, as one teacher described:

It is good that we worked towards the ultimate goal, that you implement the method at your own schools. They are on top of it, they closely monitor the progress. But on the other hand, they are flexible, I mean, you have to do it on your own now....Well, I think that is very good.

The external coach reported that their role of supervisor has developed to that of coach. They became more and more flexible, and changed details (e.g., subgroups, feedback moments) throughout the years. It was hard for them to decide: "Where do I let them go, and where do I have to intervene?"

Stakeholder support The teachers experienced support from their school leaders. They were given time to participate, and some school leaders took part in a 'Teacher Leader course', in which the teachers were trained to become Lesson Study coaches themselves. In the first year, teachers found it difficult to share information on the PLN with colleagues, as they were still experiencing what Lesson Study was for themselves. In the second year, one teacher reported that colleagues even found it annoying that she was absent during meetings at her own school when she was attending the PLN. However, in the final year, most teachers were enthusiastic about sharing knowledge within their schools. They did this by means of within-school 
Lesson Study PLNs, team meetings, and the school's newsletter, although colleagues were not always interested. On the other hand, there were concerns about the implementation of Lesson Study within the school: "I am afraid that my colleagues think it takes too much time. Probably, they should go through the phases themselves, like I did (in the PLN)."

Facilitation All teachers were given 100 h per year for PLN participation. Every teacher's schedule was free on Friday afternoons. However, most teachers reported that they exceeded the available time for the PLN, as they spent 10-15 h per month on the PLN.

The external coaches confirmed that participation by all teachers was facilitated, and that schools cooperated by shifting hours and classes when the lesson observation would take place at that school. Also, in the final year, during which the approach was implemented in their own schools, some school boards cooperated by facilitating the participation by colleagues of PLN participants in the within-school Lesson Study PLN. Schools also allowed travel time for the relatively large distances between schools.

\section{Results PLC C: This really stimulates out-of-the-box thinking}

\section{External domain - context}

Organization and structure The focus of this PLN was on designing and coaching student research in the upper secondary professional education classes. More specifically, the participants focused on increasing the quality of students' final project research report, for which research skills are needed. ${ }^{2}$ The exchange of best practices was a central component of the PLN, as was the development of curriculum coherence from lower secondary education to upper secondary education, and the development of a matching concrete research project assignment. The PLN participants designed material to support students, but also teachers, in designing and coaching a higher quality product to be generated by students.

Approximately 10 participants per year attended the PLN. Two external coaches were involved in the PLN, one from the higher education institute and one from the teacher training program at the university. The coach from the higher education institute was the chairman of each PLN meeting, and the coach from the university had content-specific expertise and worked with the participants together in subgroups. In the first year, lesson material was mainly developed and collected. From the first year on, this material was tested in practice (at their own schools) and evaluated and adjusted during the meetings.

\footnotetext{
2 Secondary education is finished with a final project and final exams. Students from general secondary education are supposed to spend $40 \mathrm{~h}$ on this project; pre-university students are supposed to spend $80 \mathrm{~h}$. The research for this project should relate to the subjects students have chosen for the final (2-3) years of their program; their final exams are also about these subjects.
} 
Activities The meetings took place at one of the participating schools. At the start, every school took care of a tour through the school in which all kinds of practical methods and ideas could be exchanged. Then the meetings started with a whole group session, in which participants updated each other on interesting, relevant facts, or ideas for the meetings. The minutes from the previous meeting were gone over together. After that, participants worked in subgroups of two to three teachers from mainly different schools in which lesson material was developed and several aspects of student research were supported and strengthened. Sometimes, guest speakers were invited to talk on relevant subjects (e.g., how to disseminate material that was developed in the PLN within the school). Outside the meetings, participants applied the materials, or collected feedback from their colleagues on the products. Half of the first year was mainly about collecting material, and after that a higher level of abstraction was reached in which they worked on their own products.

\section{Personal domain}

Satisfaction In general, teachers were satisfied with this PLN. They reported that they thought the contents of the meetings were interesting, good and satisfying. One teacher described: "I think that it is really nice that there are discussions about something, and that we have room for it and that people feel our opinion is important." Teachers were satisfied with the method used in the PLN. For example, they reported that they had influence on the objectives of the PLN, they liked the frequency of the meetings and there was openness between participants from different schools about the possibilities for improvement. One teacher explained: "I think it is fun and a great advantage to hear what is going on at other schools and what they do and don't do, and what problems they encounter. A little collegial exchange." Another teacher stated:

What I like a lot is that you collaborate with people who already put a lot of time in it, and already thought about something, so you can exchange that. So you can use a lot from each other, without redesigning on your own.

Participants were satisfied with the collaboration and active participation. They reported that they were positive about the possibilities to apply the products in practice: "That we are really able to design products that are useful too, that is a profit to me. If we had not had that, or if we were not able to accomplish that, I would not have participated anymore." From the second year on, multiple teachers mentioned that they were working on sharing knowledge and products on a larger scale.

In the first year, the teachers reported that they lacked structure in the meetings. Guidance by the external coaches was not goal-oriented, they did not stick to the agenda and meetings started slowly. In the second year, a new external coach was involved in the project, who structured goals, activities and outcomes. Furthermore, also from the second year on, some teachers disliked the lengthiness and lack of structure in the discussions. One teacher reported in the third year that it was good that now and then a new participant joined the group: "Sometimes it slows down. That is the reason why one of my colleagues has 
quit. She was thinking: I do not want to spend my time on a social group. And I get that." Multiple teachers reported in the last year that they would like more theoretical input, which was brought in by new participants.

The external coach reported that teachers wanted to develop products and wanted to get concrete: "The teachers liked that after a phase of exchange and sharing, it was time that they could get concrete and design products." The 'new' external coach reported:

In the beginning, when I had just joined, I noticed that people felt like: how should we go from here? A kind of impatience. And when you start then, and we deliver products and people can use that, yeah, then they get energy from it.

The external coach also noticed that another reason why teachers got impatient in the last year was that the participants missed having a long-term structured plan and goal.

Knowledge, skills and attitude Teachers reported that they acquired knowledge and skills. They mentioned that they constructed ideas by means of exchange with other schools: "This really stimulates out-of-the-box thinking through the knowledge and methods from other people." They also received knowledge from the school visits. By having developed criteria for the final project research reports, they reported having learned a lot: "I have to say, developing those criteria, what makes research successful, what do you have to do for it, by sharing this....that is where we develop a lot of knowledge."

The external coach added that teachers became aware of what research skills there are among students, and what were the intended objectives.

\section{Domain of practice}

In this PLN, products and materials were developed and adjusted, ready for application in practice. One teacher stated: "If you do not apply it immediately, it fades away and you actually do not use it anymore. That would be a pity." One teacher reported that she applied her developed product in practice, which was received so positively that she intended to expand it to other classes. Products were at least ready for use with participants' own target group. If other PLN participants wanted to apply products, they probably needed to be adjusted for their own teaching level. One teacher stated: "We have been thinking how we can make the products available for others, as it would be a shame if products don't get used." Teachers described how their colleagues applied and tested the products, too, and provided feedback, which was brought to the PLN afterwards and was reflected upon.

The external coach added that products need to be applied for the PLN to be effective: "Well, the material has to be tested, evaluated, and adjusted, and teachers also try to....get the more generic products they develop implemented at their own school." 


\section{Domain of consequence}

Physical outcomes of this PLN were, for example, rubrics to support teachers and students in structuring and assessing the project research reports. Also, teachers developed and adjusted lesson materials, constructed a database for exam questions, developed an Excel module and they wrote an article for publication, for example. The observations showed that participants discussed the products they developed in between meetings during the meetings. The teachers reported that they noticed the effects of the PLN's products on student results; however, they had not yet measured these effects. They noticed that students benefited, as they started structuring their final project research reports from the start. Also, one teacher reported that she expected that those students who worked with PLN material would have more research-related knowledge and skills, and more skills for developing their final project research report. Another teacher stated that he regretted the unwillingness of some colleagues to work with the products:

We have several concrete products now for them to apply. But nobody within the school is working with it, and there are a lot of people who do not want to work with it...they just told us in that way. It is not that I judge them because of that, but you just notice that when your own knowledge base grows, then you demand more, or other things from your students. Well, and they (the students) really do notice that.

\section{External domain - factors}

Shared goal and focus on a concrete outcome The subject of PLN C was students as researchers, according to the title given to it by the organizing institutes. Teachers reported that, overall, they shared the same goal during the PLN. Research and the students were the central focus of this PLN according to the coaches and the participants. The external coach supported them in reaching this goal. However, teachers also reported that the final, long-term goal was not clear for everybody. One teacher reported in the first year: "I am very goal-oriented. I want to know where we will be in about 4 years, and that is not clear to me now." Another teacher said that she felt that goals were not shared among the group, due to different motivations (e.g., intrinsically vs. extrinsically motivated).

The external coach indicated in the second year that the goals among teachers were diverse at the beginning, but by talking about it, they became clearer and more shared. However, the perceptions of the way in which students should do research continued to be varied. In the third year, the coach indicated she thought it should be clear enough what the goal was after the official time period ended (after the financing stopped) to be able to continue the PLN. She said: "I think it is still going a bit slow now, and we should finally do something about it I think."

Collective focus on student learning All teachers reported that they intended to improve students' research skills. They kept in mind that students were their target group and would have to work with the material (rubrics). 
Individual prior knowledge and motivation Most teachers reported that they had little prior knowledge concerning the subject. Two teachers described that they had more research-related skills beforehand compared to the others. Most teachers were asked by their school board to participate, but also found the subject interesting. One teacher stated: "It was a win-win situation for me". Another teacher reported: "My main focus is my own school, and I do not intend to know my PLN colleagues better than my own colleagues." Another teacher mentioned that facilitation is a very important motivator: "When you do not get hours for it, then I can imagine, I can do other things in that time." One teacher participated because he was developing a research learning path throughout the curriculum at his own school. Backgrounds (teaching level, teaching subject) varied in this PLN. Some teachers reported that this hindered teachers regarding communication and applicability of materials for their own schools, while others mentioned that it inspired them and called it an enrichment of the PLN.

One external coach reported that most respondents were personally motivated to come to the PLN, and the other coach described that many were sent by their school board. The external coach noted that the participants' motivation influenced their participation.

Trust Teachers reported that the atmosphere was pleasant and positive. Teachers respected and trusted each other. One teacher explained:

I think that everybody feels safe to say what he or she thinks and wants.

And opinions are shared a lot, and these are certainly not always positive.

So sometimes they say in a nice way, 'what do you want with that?'. I think that is a sign that everybody feels comfortable and free to say what he or she thinks.

The external coach also described the PLN as a safe environment for teachers, with a formal atmosphere.

Collaboration Teachers described the collaboration as a collegial exchange in which they got to know how things work at other schools, in which ideas, methods and materials were exchanged and discussions took place, and in which teachers were interested in each other's results. One teacher described: "I try to ask: how do you do that (at your school)? We are doing it like this. This collaboration stimulates thinking in another way." From the second year on, they worked in subgroups, in which the external coach also participated. Teachers reported that the core group was always present during meetings and participated actively. Those who did not, had quit the PLN. One teacher mentioned that he found it hard to collaborate aside meetings, due to the distance between schools. They worked together in subgroups by discussing, designing, experimenting on their own (some experimenting was also done by others), and adjusting again. One teacher reported mainly having collaborated with a colleague from her own school. However, another teacher collaborated with a participant from another school:

I have this approach, you have that approach, and then we come together like this. So I have sent the results from the workshop to her, and she shares what she found at her school....In that way, we can complement each other. 
Participants reported working approximately $8 \mathrm{~h}$ per month on PLN activities.

The external coach reported that the collaboration was good in this group. There were some participants who talked more and asked more questions than others: "Some teachers like to find out things for themselves and only show the material when it is complete, and others do not mind showing concepts to others. Well, then you get different input, of course." In the final year, however, the external coach mentioned that there were three participants who were very active in comparison to the rest of the group.

Reflective dialogue Teachers reported they had many discussions during the PLN meetings. One teacher reported: "There are many fun and interesting discussions, and we all have our own expertise and vision." These were content-specific, or were about the implementation of PLN products in the schools. One teacher stated that he thought the discussions were qualitatively good, but very content-specific. He wanted to bring in more theoretical background. Another teacher stated the discussions were often too specific and too long.

The external coaches reported that there were discussions about practical as well as content-related issues. Also, the application of products was evaluated in the meetings. Additionally, the observations showed that the facilitation by the school to participate was discussed multiple times.

Leadership From the second year on, there were two external coaches actively involved in the PLN. They had different roles. One acted as coordinator, and took care of all the organizational issues of the PLN. He emailed the agenda, was chairman at meetings, and organized, for example, the publication of an article in a subject-specific journal about the PLN and its products. The other external coach actually had three different roles. As external coach she gave content-specific input, as a coach she monitored and reflected on the process, and as co-participant she was part of different subgroups and produced materials. Teachers reported liking the division of roles between the external coaches. Following the switch in coaches after the first year, the PLN became more goal-oriented and more concrete. However, some teachers still missed concreteness in the discussions, and would have liked more theoretical background for their activities and products.

The external coach confirmed the distribution of tasks between the two coaches. In the third year, she noticed that a new challenge was coming to this PLN if the participants were to be able to sustain the PLN. She stated: "How do we keep it useful....But I think this is just the way it is. We developed what we wanted and now we should make up something new to continue. But we will think of something." The observations showed that the external coach was coordinating, but also actively participating in the meetings.

Stakeholder support Some teachers reported that they had a similar group within the school with whom they shared knowledge and materials. One teacher, who came with a colleague to the PLN, reported discussing a lot with this colleague and was working together on a workshop for other colleagues within the school. Most teachers reported that they had contact with their superior about the PLN. However, others described that their colleagues were not interested, and some colleagues did not even know what the PLN was about. One teacher stated: "We have several concrete products now for them to apply. But nobody within the school is working with it, 
and there are a lot of people who do not want to work with it...they just told us like that." An objective of this PLN was to bring the products and materials into the school, which was a common subject of discussion for them. One teacher stated: "I hope to share the products of the PLN within my school, so others can profit from it too." This focus led to actively providing input in team meetings within the school, and meetings with the school board, and workshops. One of the teachers reported that some schools were very active in keeping up with the PLN's progress, while in other schools this depended on the participant's efforts.

The external coach confirmed that participants were dedicated to sharing their products and material within the schools.

Facilitation Some teachers reported finding how they were facilitated very important, but others did not: "I honestly have to admit that the facilitation is not interesting for me. I always get an overview of my hours that I should put into tasks, I do not care." Some teachers reported they were not given time to participate, others were given time to participate, or reported the PLN time as part of their 'task time' (i.e., hours that teachers are obliged to spent on tasks other than their instruction). Some had to attend the PLN meeting on their day off. The teachers reported that there was one participant who had quit due to facilitation issues.

The external coach reported that facilitation kept being an issue for discussion in the PLN. He stated: "Teachers notice how different participants are facilitated. This leads to commotion, and keeps being a subject for recurring discussions." In the third year the external coach reported that facilitation influenced active participation: "There are teachers who are given freedom from tasks/hours. Then you feel obliged to put in extra effort."

\section{Synthesis of each case}

Although PLN A participants are generally satisfied and seem to have developed their knowledge, skills and attitudes regarding research, findings regarding application in practice and transfer to participants' schools are mixed. Both the coach and several teachers missed a 'next step' of transfer of PLN results to participants' schools, experiencing it more like a (temporary) 'project' than as a way to collaboratively developing a network as described in the context description (see External domain-context). Lack of clarity about the goals and lack of coherence between themes, lack of actual collaboration during the PLN meetings and in-depth discussions, or reflective dialogue, and a large variation in participant backgrounds, are mentioned by different respondents and could be possible reasons. Both several teachers and the coach reported a lack of collaboration beyond exchanging experiences. Teachers did not really work together much within the meetings, let alone outside the meetings. Some teachers applied the knowledge and skills learnt in supervising their students and in their own research, and became more aware of the variety of student research within the network of schools. Others wonder about really being able to apply what they learn from others in their own school. Perspectives both on collaboration and network development appear to be varied. Even if taking place, the coach reports network development activities to be one-way: ideas 
were taken from PLN to the schools, but not the other way around; nor were they really developed by schools together. Some respondents do mention examples of network development, however, such as the teachers who applied knowledge and skills developed in the network in the research group within their school. One participant worked on establishing a common research structure and alignment in the school network. Others mentioned that the PLN was part of a bigger whole in their school and that their colleagues were also invited to join meetings when relevant.

Lesson Study PLN B teachers enjoyed working on developing lessons together, and reported to have learnt about student thinking, didactics, and contact with students. Respondents also reported applying both the developed lesson(serie)s as well as the LS approach itself in their schools. In the LS approach, developing and teaching particular lessons is a core part of the structured approach. The teachers visited each others' schools for the application phase and really worked together. At the same time, both teachers and the coach reported feasibility problems regarding the investigation and planning parts of the cycle, especially for the long term. Still, teachers also used the approach with other colleagues in their own schools and one teacher even reported other teachers at her school were applying it too. This PLN seems to have contributed more to developing the network as a whole as well. They collaborated beyond sharing experiences, were in contact outside network meetings too-also via social media, and some of their school leaders also participated in a teacher leader course focused on Lesson Study. Some school boards also facilitated other colleagues than PLN members to participate in within-school Lesson Study. Despite some challenges in the first years of the PLN, in the end most teachers were enthusiastic about the transfer of PLN-outcomes to their own schools.

In PLN C about students as researchers teachers were generally satisfied about the content of the meetings and collaboration. They worked on sharing both knowledge and products (e.g., rubrics for assessing project research reports, a database for exam questions), which were applied at their own schools. Although not systematically measured, teachers also reported that their students benefitted from the materials developed in the PLN. Teachers also reported about their colleagues in their schools applying their materials and taking colleagues' feedback back into the PLN to reflect upon. Most respondents seem to be positive, but one teachers reports that colleagues did not want to. It took a while before goals, activities and outcomes were structured in this PLN; and some still missed a long-term structured plan and goal in the end. Collaboration was generally experienced as positive, although in the end not all participants actively participated, according to the coach. Facilitation by the schools of the PLN participants and stakeholder support seemed to remain an issue.

\section{Conclusions and discussion}

The research questions of this study relate to the outcomes in the different domains distinguished in the Interconnected model of professional growth (Clarke and Hollingsworth 2002). 


\section{What are the professional development outcomes for teachers participating in PLNs?}

In general, teachers and external coaches reported that they were satisfied with their PLN. The teachers gained knowledge and skills, and their professional attitude changed through participation in the PLN (personal domain). PLNs B and C reported having produced lesson material and lesson series, which were received positively by their students. PLN A aimed to reach alignment among the schools regarding coaching research of pre-service teachers, and regarding research in general, which did not result in specific products (domain of consequence). Additionally, all PLNs reported that they had applied the knowledge, skills and products in their practice (domain of practice). There were some critical notes, on the other hand. The participants and external coach in PLN A reported that they experienced a lack of interaction and depth in the PLN. In PLN B, this varied. In PLN B, the methodology was experienced as very intensive, and time-consuming. Additionally, the external coach doubted whether the approach was suitable for all of the teachers, especially those who did not start with a research-based attitude. In PLN C, participants reported that they lacked a long-term goal, and needed input by means of new participants to keep being maintain their motivated motivation in the last year. Additionally, although some (indirect) examples of results for student learning were reported, none of the participants actually studied this explicitly. These issues may have consequences for teacher learning within the PLN and the schools, as described below.

\section{What is the role of the external domain (sources of information, stimuli and support) in teacher professional growth in PLN participation?}

Leadership and structure seemed to play an important role in the achievement of positive outcomes in all domains, and could impact multiple other influential factors. In PLN B, where the goals and activities were the most structured (following the Lesson Study approach), the application to practice was most evident. Also, concrete steps towards school improvement were taken, and were structured and set out from the beginning. At the same time, leadership was shared by means of the subgroups and the feelings of ownership among teachers increased. A growing leadership capacity could also be seen in PLN C. The balance between providing structure to monitor the progress of the PLN and leaving room for the teachers' own contributions, between vertical and shared leadership, has been found promising in other research (Binkhorst 2017). Moreover, the development of leadership capacity has previously been found to be important for effectiveness, but also for sustainability and knowledge dissemination across the network (e.g., Harris and Jones 2010; Stoll and Temperley 2009). In PLNs A and C, vertical leadership was less present and structured, which probably led to haziness about the goals. The PLNs had not been structured for the long term, which might have impact on the teachers' motivations and hence, its future continuity (Poortman and Brown 2018). 
Besides leadership, structured activities with a relation to practice are important. The lack of coherence between themes in A2 meetings in PLN A, and the poorly received relation to practice of the activities hindered professional development, as has also been found in the literature (e.g., Garet et al. 2001; Handelzalts 2009). The relation to practice seems especially important, as both PLN B and PLN C reported applying their products in practice, and had spread them among their colleagues.

Third, having a shared goal seemed to depend on the prior knowledge and motivations of participants. In PLN A, one objective was to obtain alignment between schools at the level of student theses, and ultimately at the level of teachers' research. Participants were stimulated not to stop at improving their guiding skills, but to take the next step and continue with research within and across their own schools. At the first level of research within the schools (guidance of students), participants were satisfied, gained knowledge, skills and awareness and reported applying these. However, the coordinators and researchers within schools aimed for the next level. The PLN goal did not appear to be 'shared,' as participants with different backgrounds and prior knowledge had different aims. Also, participants experienced a lack of expertise within the PLN and felt that this hindered deep learning. The group for the A2 meetings also varied a lot, which hindered feelings of ownership (Schaap and de Bruyn 2017), and consequently limited collaboration, trust and reflective dialogue.

Another crucial aspect is collaboration. In both PLN B and PLN C, teachers collaborated in subgroups and produced a variety of outputs in the domain of consequence, such as multiple lesson materials and/or series. In PLN B, for example, teachers were highly stimulated to collaborate in an effective way; they all had to execute the lessons, by which they were given shared responsibility, which led to ownership. Although the approach was time-consuming, teachers were motivated to spend these hours, and also invested their free time. In PLN C, teachers also reported collaborating with their PLN colleagues outside the meetings, and spent time preparing for meetings. In PLN A, collaboration in general was restricted to the meetings and remained superficial, resulting in limited output and satisfaction.

Lastly, regarding reflective dialogue teachers and the external coach in PLN A reported, for example, that discussions did not reach deeper levels of content and that interaction was lacking, factors that are necessary for effective teacher learning (e.g., Hargreaves et al. 2010; Lomos et al. 2011). In PLN B this varied but was at least focused on explicitly as part of the Lesson Study approach. In PLN C discussions were reported to be frequent and interesting, but also too specific and too long. These varying results show the challenge of stimulating the right level of reflective dialogue (Schaap and de Bruyn 2017).

\section{From teacher learning to school improvement}

As shown in Fig. 1, the aim of PLNs is that outcomes of the personal, consequence and practice domains (Clarke and Hollingsworth 2002) must be transferred to the participants' own schools. This means that the knowledge, skills, attitudes and products should not simply stay with the participants themselves, 
but need to be spread within the school (and across the network) (e.g., Chapman 2014; Harris and Jones 2010).

The project studied in this paper prescribed that the PLNs should consist of a mix of teachers from different schools who had graduated from higher professional and from university teacher education; that members should work on a specific approach or product as the outcome; that the PLN should have regular (monthly) meetings for at least 1 year; and that it should be guided by at least one teachingsubject expert in the area of research, curriculum design or didactic approach. The detailed findings show how different PLNs working within the same project and the same basic conditions can vary hugely in how they work towards their aims, resulting in different types of results at different levels both for teachers and participating schools (even within PLNs). In PLN A, for example, collaboration seemed to be about 'storytelling' and 'sharing' (Little 1990) rather than 'joint work' as defined by Vangrieken et al. (2017, p. 23): joint interaction in the group in all activities that are needed to perform a shared task. There are examples of network development in all cases, from PLN to schools and even in some instances back to the PLN, although participants' perspectives varied on this subject. In PLN B, for example, activities appeared to be more structured and were explicitly focused on application in the classroom, as part of the Lesson Study approach. Collaboration in terms of joint work (Vangrieken et al. 2017) is a more self-evident part of this approach, as is reflection. Moreover, school leaders of the participating teachers and schools were more actively involved as part of the approach: they participated in a 'Teacher Leader course' and were invited regularly to be informed about the approach and PLN progress. Although some teachers question the applicability of Lesson Study as an approach in their school, both resulting lessons and the approach were applied at participants' school, also in other classes (e.g., by participants' colleagues). School boards and school leaders related to this PLN also appeared to be more supportive in terms of facilitation of PLN participants, and their colleagues who were involved in implementing Lesson Study in their schools.

In this paper PLNs were broadly defined (Poortman and Brown 2018, p.11), as any group who engage in collaborative learning with others outside of their everyday community of practice, in order to improve teaching and learning in their school(s) and/or the school system more widely. The expectations associated with communities and networks is that active collaboration leads to learning of teachers, and ultimately to improved student learning, also in the wider community in which the participating teachers work (e.g., Rose et al. 2017).

Poortman et al. (2020) raise the question about essential features of PLNs, of which there are many-slightly varying- lists in the literature (see influencing factors, this paper). The question is, if educators come together with the purpose of actively collaborating to learn how to improve their teaching and their students' learning and one or more of these factors are not fulfilled in an successful way, may they not be called a PLN? Moreover, influencing factors such as reflective dialogue, for example, are defined very differently in different studies (Doğan and Adams 2018). Further defining the concept as a whole is therefore crucial if PLNs are to provide a useful tool for improving teacher and student outcomes (Poortman et al. 2020). 
The coaches in all PLNs organized the meetings, were available as content experts, and process coaches, however, they were not provided with a generally discussed and agreed-upon structured approach to facilitate PLN meetings in advance. The lack of a long-term structured plan and goal was explicitly reported in PLN C. In agreement with Stoll et al. (2006), the PLNs in this study seemed to go through different stages of development, where agreement about goals, trust, and a focus on concrete products and student outcomes appeared to develop over the years. At the same time, lack of depth was still reported in the final year, the focus on student outcomes was not supported by any research evidence by the participants, and there was still much left to be desired in terms of substantial results and network development. To promote achieving the desired outcomes, first, the role of the external coach should be clear, balanced and structured. There should be a balance between vertical and shared leadership (Binkhorst 2017). Moreover, PLNs could be considered as programs that need to be carefully designed, already beforehand (Hargreaves et al. 2015): 'there is no shortcut for establishing a shared vision and goals', for example (Hargreaves et al. 2015, p. 316). Even though the PLNs in this study benefitted from a longer-term project, a more structured approach not only to guiding, but also to establishing PLNs in the first place sufficiently early in the process, seems crucial to help achieve school improvement in the long term.

\section{Limitations}

In this study, our findings were mainly based on self-report by the PLN participants and external coaches. However, by using different perspectives (participants, external coaches, and observations by the researchers), we were able to validate our findings on the working mechanisms within the PLNs, in a descriptive way, however. The ultimate goal of the PLNs was school improvement. We did not directly measure outcomes at the school level. The duration and design of the study was not suitable for this purpose. Additionally, the definition issue raised in the previous section needs to be addressed to be able to make experimental studies to measure PLN impact even possible (Gore et al. 2017).

\section{Implications for further research}

Further research could focus more on the relationship between aspects such as reflective dialogue (see, for example, Horn and Little 2010, in Van Lare and Brazer 2013), student achievement outcomes and sustainability (Poortman et al. 2020; Doğan and Adams 2018). Further research also needs to focus more on development of the network beyond PLN members transferring PLN-findings to their schools. An activity system lens (Engeström 2001), including expansive learning focused on learning by the PLN as a whole, and the role of boundary crossers (Malin and Brown 2019) could be used to allow for a more broad network perspective including the process 
and factors from teacher learning and practice to development of the entire network participating teachers and schools are part of.

Acknowledgements This study was funded by the Dutch Ministry of Education, Culture, and Society. The authors would like to thank the involved respondents for their cooperation.

Open Access This article is licensed under a Creative Commons Attribution 4.0 International License, which permits use, sharing, adaptation, distribution and reproduction in any medium or format, as long as you give appropriate credit to the original author(s) and the source, provide a link to the Creative Commons licence, and indicate if changes were made. The images or other third party material in this article are included in the article's Creative Commons licence, unless indicated otherwise in a credit line to the material. If material is not included in the article's Creative Commons licence and your intended use is not permitted by statutory regulation or exceeds the permitted use, you will need to obtain permission directly from the copyright holder. To view a copy of this licence, visit http://creativecommons.org/licen ses/by/4.0/.

\section{References}

Andrews, D., \& Lewis, M. (2004). Building sustainable futures: Emerging understandings of the significant contribution of the professional learning community. Improving Schools, 7(3), 129-150. https://doi.org/10.1177/1365480204047345.

Bauer, S. C., Van Lare, M., Brazer, S. D., \& Smith, R. (2015). Teacher Leadership in Collaborative Teams. Renewed Accountability for Access and Excellence: Applying a Model for Democratic Professional Practice in Education (Vol. 131). Lanham: Lexington Books.

Binkhorst, F. (2017). Connecting the dots-Supporting the implementation of teacher design teams. Doctoral thesis. University of Twente, The Netherlands.

Bolam, R., McMahon, A., Stoll, L., Thomas, S., \& Wallace, M. (2005). Creating and sustaining effective professional learning communities. DfES Research Report RR637: University of Bristol. Retrieved April 27, 2020 from https://dera.ioe.ac.uk/5622/1/RR637.pdf.

Bryk, A., Camburn, E., \& Louis, K. S. (1999). Professional community in Chicago elementary schools: Facilitating factors and organizational consequences. Educational Administration Quarterly, 35(5), 751-781. https://doi.org/10.1177/0013161x99355004.

Chapman, C. (2014). From within- to between- and beyond-school improvement: A case of rethinking roles and relationships? ICSEI monograph series. Retrieved April 27, 2020 from https://www. icsei.net/the-icsei-monograph-series/.

Clarke, D., \& Hollingsworth, H. (2002). Elaborating a model of teacher professional growth. Teaching and Teacher Education, 18, 947-967.

Denzin, N. K. (1978). The research act: A theoretical introduction to sociological methods (2nd ed.). New York: McGraw Hill.

Doğan, S., \& Adams, A. (2018). Effect of professional learning communities on teachers and students: Reporting updated results and raising questions about research design. School Effectiveness and School Improvement, 29(4), 634-659.

Engeström, Y. (2001). Expansive learning at work: Toward an activity theoretical reconceptualization. Journal of Education and Work, 14(1), 133-156.

Fernandez, C., \& Chokshi, S. (2002). A practical guide to translating lesson study for a US setting. Phi Delta Kappan, 84(2), 128-134. https://doi.org/10.1177/003172170208400208.

Fernet, C., Senécal, C., Guay, F., Marsh, H., \& Dowson, M. (2008). The work tasks motivation scale for teachers (WTMST). Journal of Career Assessment, 16(2), 256-279. https://doi. org/10.1177/1069072707305764.

Garet, M. S., Porter, A. C., Desimone, L. M., Birman, B., \& Yoon, K. S. (2001). What makes professional development effective? Analysis of a national sample of teachers. American Educational Research Journal, 38(3), 915-945. https://doi.org/10.3102/00028312038004915.

Geijsel, F. P., Sleegers, P. J. C., Stoel, R. D., \& Krüger, M. L. (2009). The effect of teacher psychological, school organizational and leadership factors on teachers' professional learning in Dutch schools. The Elementary School Journal, 109(4), 406-427. https://doi.org/10.1086/593940. 
Gore, J., Lloyd, A., Smith, M., Bowe, J., Ellis, H., \& Lubans, D. (2017). Effects of professional development on the quality of teaching: Results from a randomised controlled trial of quality teaching rounds. Teaching and Teacher Education, 68, 99-113.

Hadfield, M., \& Ainscow, M. (2018). Inside a self-improving school system: Collaboration, competition and transition. Journal of Educational Change, 19(4), 441-462.

Handelzalts, A. (2009). Collaborative curriculum development in teacher design teams. Enschede: University of Twente.

Hargreaves, A., Lieberman, A., Fullan, M., \& Hopkins, D. (2010). Second international handbook of educational change. Dordrecht: Springer.

Hargreaves, A., Parsley, D., \& Cox, E. K. (2015). Designing rural school improvement networks: Aspirations and actualities. Peabody Journal of Education, 90(2), 306-321.

Harris, A., \& Jones, M. (2010). Professional learning communities and system improvement. Improving Schools, 13(2), 172-181. https://doi.org/10.1177/1365480210376487.

Horn, I. S., \& Little, J. W. (2010). Attending to problems of practice: Routines and resources for professional learning in teachers' workplace interactions. American Educational Research Journal, 47(1), 181-217. https://doi.org/10.3102/0002831209345158.

Huffman, J., \& Jacobson, A. (2003). Perceptions of professional learning communities. International Journal of Leadership in Education, 6(3), 239-250. https://doi.org/10.1080/136031202200001 7480.

Katz, S., \& Earl, L. (2010). Learning about networked learning communities. School Effectiveness and School Improvement, 21(1), 27-51. https://doi.org/10.1080/09243450903569718.

Lai, M. K., \& McNaughton, S. (2016). The impact of data use professional development on student achievement. Teaching and Teacher Education, 60, 434-443. https://doi.org/10.1016/j. tate.2016.07.005.

Landis, J. R., \& Koch, G. G. (1977). The measurement of observer agreement for categorical data. Biometrics, 33(1), 159-174. https://doi.org/10.2307/2529310.

Lee, D. H. L., \& Lee, W. O. (2018). Transformational change in instruction with professional learning communities? The influence of teacher cultural disposition in high power distance contexts. Journal of Educational Change, 19(4), 463-488.

Lieberman, A. (2000). Networks as learning communities shaping the future of teacher development. Journal of Teacher Education, 51(3), 221-227. https://doi.org/10.1177/0022487100051003010.

Lieberman, A., \& Grolnick, M. (1996). Networks and reform in American education. Teachers College Record, 98(1), 7-45.

Little, J. W. (1990). The persistence of privacy: Autonomy and initiative in teachers' professional relations. Teachers College Record, 91(4), 509-536.

Lomos, C., Hofman, R. H., \& Bosker, R. J. (2011). Professional communities and student achievement-A meta-analysis. School Effectiveness and School Improvement, 22(2), 121-148. https:// doi.org/10.1080/09243453.2010.550467.

Louis, K. S., \& Kruse, S. D. (Eds.). (1995). Professionalism and community: Perspectives on reforming urban schools. Thousand Oaks: Corwin.

Louis, K. S., Leithwood, K., Wahlstrom, K. L., Anderson, S. E., Michlin, M., \& Mascall, B. (2010). Learning from leadership: Investigating the links to improved student learning. Center for Applied Research and Educational Improvement/University of Minnesota and Ontario Institute for Studies in Education/University of Toronto, 42, 50.

Malin, J. R., \& Brown, C. (2019). Joining worlds: Knowledge mobilization and evidence-informed practice. In J. Malin \& C. Brown (Eds.), The role of knowledge brokers in education (pp. 1-12). London: Routledge.

Mercer, N. (2008). Talk and the development of reasoning and understanding. Human Development, $51,90-100$.

Poortman, C. L., \& Brown, C. (2018). The importance of professional learning networks. In Networks for learning (pp. 10-19). Routledge.

Poortman, C.L., Brown, C. \& Schildkamp, K. (2020). Professional Learning Network processes and the link to student outcomes: a conceptual model of impact and research opportunities. In Presented at ICSEI 2020, Marrakech, Morocco, January 6-10.

Prenger, R., Poortman, C. L., \& Handelzalts, A. (2017). Factors influencing teachers' professional development in networked professional learning communities. Teaching and Teacher Education, 68, 77-90. 
Rose, J., Thomas, S., Zhang, L., Edwards, A., Augero, A., \& Roney, P. (2017). Research learning communities: Evaluation report and executive summary. Education Endowment Foundation.

Ryan, R. M., \& Deci, E. L. (2000). Self-determination theory and the facilitation of intrinsic motivation, social development, and well-being. American Psychologist, 55(1), 68-78.

Schaap, H., \& de Bruyn, E. (2017). Elements affecting the development of professional learning communities in schools. Learning Environments Research, 21(1), 109-134. https://doi.org/10.1007/ s10984-017-9244-y.

Stoll, L. (2010). Connecting learning communities: Capacity building for systemic change. In A. Hargreaves, A. Lieberman, M. Fullan, \& D. Hopkins (Eds.), Second international handbook of educational change (pp. 469-484). Dordrecht: Springer.

Stoll, L. (2015). Using evidence, learning and the role of professional learning communities. In C. Brown (Ed.), Leading the use of research and evidence in schools (pp. 54-65). London: IOE Press.

Stoll, L., Bolam, R., McMahon, A., Wallace, M., \& Thomas, S. (2006). Professional learning communities: A review of the literature. Journal of Educational Change, 7(4), 221-258. https://doi. org/10.1007/s10833-006-0001-8.

Stoll, L., \& Temperley, J. (2009). Creative leadership teams: Capacity building and succession planning. Management in Education, 23(1), 12-18.

Thurlings, M., \& den Brok, P. (2014). Leraren leren als gelijken: Wat werkt? [Teachers learn as equals: What works?]. NRO report. Retrieved April 27, 2020 from https://www.nro.nl/wp-conte nt/uploads/2014/05/Leraren-leren-als-gelijken-wat-werkt.pdf.

Van Lare, M. D., \& Brazer, S. D. (2013). Analyzing learning in professional learning communities: A conceptual framework. Leadership and Policy in Schools, 12, 374-396. https://doi. org/10.1080/15700763.2013.860463.

Van Veen, K., Zwart, R., Meirink, J., \& Verloop, N. (2010). Professionele ontwikkeling van leraren. Een reviewstudie naar effectieve kenmerken van professionaliseringsinterventies van leraren [Professional development of teachers. A review study after effective characteristics of interventions for professionalization among teachers]. ICLON/Expertisecentrum Leren van Docenten. Retrieved April 27, 2020 from https:/www.bvekennis.nl/wp-content/uploads/documents/110010-ICLON-review-professionele-ontw-leraren-0.pdf.

Vangrieken, K., Meredith, C., Packer, T., \& Kyndt, E. (2017). Teacher communities as a context for professional development: A systematic review. Teaching and Teacher Education, 61, 47-59.

Vescio, V., Ross, D., \& Adams, A. (2008). A review of research on the impact of professional learning communities on teaching practice and student learning. Teaching and Teacher Education, 24(1), 80-91. https://doi.org/10.1016/j.tate.2007.01.004.

Voogt, J., Westbroek, H., Handelzalts, A., Walraven, A., McKenney, S., Pieters, J., et al. (2011). Teacher learning in collaborative curriculum design. Teaching and Teacher Education, 27(8), 1235-1244.

Publisher's Note Springer Nature remains neutral with regard to jurisdictional claims in published maps and institutional affiliations. 